\title{
AN ANALYSIS OF PIDD ${ }^{2}$ CONTROLLERS OPTIMAL ADJUSTING ALGORITHM IN MPP FUEL PREPARATION SYSTEM
}

\author{
Andrii Simanenkov \\ Department of Exploitation of marine electrical equipment and means of automation \\ Kherson state marine academy \\ 20 Ushakova str., Kherson, Ukraine 73021 \\ symon2007@ukr.net
}

\begin{abstract}
The possibility of introducing PIDD ${ }^{2}$ controllers into adaptive automatic control systems using the proposed algorithm for finding the optimum adjusting parameters of the specified controller is considered. The carried out analysis of the structural implementation of the PIDD $^{2}$ controller and the estimation of the filter time constants of the first and second order differentiation units made it possible to formulate the structure of the PIDD ${ }^{2}$ controller-based adaptive automatic control system.

The proposed algorithm for finding the optimum adjusting parameters of the PIDD ${ }^{2}$ controller consists in a purposeful procedure for finding the optimal point with the maximum value of the transfer factor of the controller in the parameter space, taking into account the preset stability margin.

In determining the steps of the algorithm, the structural and parametric optimization of the filters of the differentiation links is performed, which make it possible to reduce the problem only to the search for adjusting parameters of the controller.

The work of the proposed algorithm is illustrated by the example of an automatic control system, where the mathematical model of the heat exchanger unit of the fuel combustion engine of the internal combustion engine is the controlled object.

Analysis of transient processes and frequency responce of the simulated system shows the qualitative superiority of the adaptive automatic control system with the optimally tuned PIDD ${ }^{2}$ controller over the conventional automatic system with a PID controller.

The versatility of the algorithm and the ability to periodically adjust the adjustments of the controller are also noted.

Keywords: marine internal combustion engine, PIDD $^{2}$ controller, adaptive automatic control system, fuel preparation system, search algorithm.
\end{abstract}

\section{Introduction}

Factors that have the greatest impact on fuel consumption are: the state of weather conditions and the direction of currents, the laying of optimal routes for ships, and maintaining a constant output power when operating marine internal combustion engines (MICE). Studies [1] prove that the minimum fuel consumption is achieved to a greater extent by maintaining a constant output power of the MICE, and deviation from this criterion leads to overconsumption.

It is known [2], the parameters that make the greatest impact on the MICE efficiency are the temperature and pressure of the coolant, the temperature and pressure of the lubricaiting oil and the temperature and pressure of the fuel in the fuel line of the engine. Adjustment of automatic control systems for temperature and pressure of lubricating oil and coolant faces a number of difficulties that are related to the design limitations of heat exchangers of these systems. So, the most interesting are automatic fuel preparation systems.

Modern marine power plants (MPP) use an energy carrier, should be prepared in accordance with the stringent conditions of the manufacturer's factory. When analyzing the existing studies in the field of automatic control of the MICE fuel preparation, it is concluded that the main direction of automation of these systems is maintaining the fuel viscosity within wide limits without taking into account the wave-like changes in the temperature of the energy carrier [3]. Fuel preparation process is characterized as slow. However, poorly predicted changes in the input parameters of the heat-recovery apparatus (fuel pressure and temperature, heating steam pressure and temperature, ambient temperature) make the conventional PID controller ineffective. After all, it does not provide sufficient accuracy in regulating the output parameters of the heat exchanger, when the input parameters vary widely. Therefore, the problem of effective automatic control in MPP fuel preparation systems is urgent and requires a more efficient method of solution. 


\section{Analysis of existing solutions of the problem}

The issues of increasing the efficiency of the MICE operation, reducing fuel consumption, reducing $\mathrm{NO}_{\mathrm{x}}$ and sulfur emissions have been relevant for several decades and are being studied by researchers around the world. In [4], the authors study the improvement of the fuel combustion quality by optimizing the inflammatory spark and modeled the wear process of the electrodes. Work [5] proposes to improve environmental safety and efficiency of operation of power plants using the operational efficiency criterion, introduced into the hierarchical structure of the facility. The authors of [6] study the processes of fuel distribution in a diesel power plant using the input of indicators that determine laser-induced fluorescence in the process of fuel combustion. Work [7] offers a system for mixing heavy and light grades of fuels with the subsequent emulsion of the resulting mixture with water. That allows to reduce the ICE operating costs and $\mathrm{NO}_{\mathrm{x}}$ and sulfur emissions. In [8], the improvement in the fuel combustion quality is achieved using a plasma jet, which increases the rate of the oxidation reaction due to the increase in the number of active combustion centers. Reduction of $\mathrm{NO}_{x}$ and sulfur emissions, as well as improvement of combustion quality, is achieved in [9] by applying a dual-fuel combustion mode (jet ignition). This mode allows better control of the combustion process by modulating the reactivity of the fuel, depending on the operating conditions of the engine. In [10], the authors propose an increase in the environmental and economic performance of ICE by introducing an algorithm for selecting optimal operating modes in the engine control system.

These works allow to state that the direction of modernization of the automatic control system itself for the preparation of fuels is insufficiently studied. Despite this, the author carries out a study on the derivation of the algorithm for adapting the automatic control system for fuel preparation as a control object with a wide transport delay.

A poorly predicted change in the dynamic characteristics of controlled facilities with a significant delay in transport reduces the effectiveness of traditional methods of automatic regulation, while making the controller not optimal. The adjustment becomes either weak, providing optimal control of the parameters of the control object, or too pointed, which can lead to loss of stability of the system. The replacement of physical controllers by software-implemented in microcontrollers, without changing the principles and control algorithms proved to be ineffective. This increases the interest in studying, modeling and development of adaptive systems.

The classical adaptive controller should ensure the high-quality functioning of the automatic control system (ACS), as well as observance of a given stability margin when the dynamics of the object change, without intervention from the operating personnel. Despite a large number of research and development on adaptive control methods and algorithms, including self-adjusting in the field of automatic adjusting systems (AAS), there are still no convincing examples that could compete with traditional regulating schemes [11, 12].

Most of the existing methods of adaptive control require an adequate mathematical description of the adjusting object and the simulation model built on its basis.

In general, the methods of constructing adaptive devices for recognizing changes in the properties of an object, occurring and further identification, known from publications, use either a periodic input into the open circuit of special generated disturbances, or the output of a closed loop to the regime of stable self-oscillations. Use to adapt the passive statistical proximity of the operational variable and its simulated value leads to unacceptable errors in determining the parameters in the adopted model structure [13].

From active methods, the most expedient is to consider the change in the reference to the controller in a closed control loop. With this approach, adaptation is the final step in the ACS synthesis and is performed when the system is put into operation [14]. This method is of the greatest interest for further research and modernization, due to the introduction of an adaptive control system structure with PIDD $^{2}$ controller and an algorithm for automatically adjusting for the adjustments of its parameters.

The question of the algorithm for finding the optimal adjustments of PID controllers with real differentiation is considered in a number of publications. An analytical method is presented in [15], the criterion of optimality of which is the requirement of a minimal integral criterion. 
Minimization is carried out with a limitation on the value of the frequency index of the oscillation system, which corresponds to the restriction on the arrangement on the complex plane of the complex frequency characteristic (CFC) of the open system. This characteristic should not go inside the circle $\mathrm{M}$ with the index $\mathrm{M}_{\max }$. Determination of optimal adjustments by the described method is recommended to be carried out by the method of successive approximations in the format of a dialogue with an electronic computer.

Also important are algorithms that use fairly simple formulas that allow to determine the controller's adjustments by the transient response of the control object [16].

\section{The aim and objectives of research}

The aim of research is development of an efficient algorithm for PIDD $^{2}$ controller optimal adjustments to improve the performance of the adaptive ACS of MICE fuel preparation.

To achieve this aim, the following tasks are set:

- to identify the transfer function of the PIDD ${ }^{2}$ controller, with the transfer functions of the differentiation filters of the first and second orders;

- to determine the algorithm for a targeted search for the optimal point with the maximum transmission factor to the controller for the selected stability margin;

- to calculate and conduct a comparative analysis of the transition process curves and the CFC of the control object with the constructed adaptive (based on the PIDD ${ }^{2}$ controller) and conventional (based on the PID controller) system models.

\section{Structural realization of multi-parametric PIDD $^{2}$ controller in adaptive automatic con- trol systems}

The necessity of an integral component in the algorithm of PI controllers is dictated by the desire to eliminate residual irregularity of regulation that takes place in systems with $\mathrm{P}$ controllers. But the introduction of the integral component adversely affects the stability margin of the control loop, since it increases the lag in the frequency responsence phase of the open loop. According to the positive effect of the action of the differential component in the PID control law is to compensate for the negative effect of the integral component of the stability margin of the system. Therefore, the criterion of optimality can be based on the requirement of mutual compensation of the integral and differential components for the maximum possible resonance part of the system.

In modern studies related to automatic control algorithms, there are more and more proposals for introducing higher-order derivatives in the controlled law. These trends find negative criticism, because with multiple differentiation, there is a need for enhanced signal filtering. Even the introduction of the first derivative into the functioning algorithms in practice faces a number of serious difficulties. And the use of multiple differentiation can make these difficulties irresistible [17-19]. However, this problem is solved quite effectively by using high-frequency filters.

The transfer function of the PID controller in modern microprocessor controllers looks like this:

$$
\mathrm{W}_{\mathrm{p} . \mathrm{p} .}^{\mathrm{PID}}(\mathrm{s})=\mathrm{K}_{\mathrm{p}} \cdot\left(1+\frac{1}{\mathrm{~T}_{\mathrm{I}} \cdot \mathrm{s}}+\frac{\mathrm{T}_{\partial 1} \cdot \mathrm{s}}{\mathrm{T}_{\mathrm{f} 1} \cdot \mathrm{s}+1}\right),
$$

where $K_{p}$ - the transfer factor of the controller; $T_{I}$ - the time constant of integration; $T_{\partial 1}-$ the time constant of differentiation with respect to the derivative of the first order; $T_{f 1}$ - the time constant of the filter for the first-order derivative.

The need for real differentiation in PID controllers is due to the presence of random, mostly high-frequency noises in the input signal of the controller. In addition, in modern microprocessor controllers with digital implementation of controlled laws, constructive sources of noise are also added, due to the conversion of analog signals to discrete ones.

Usually, during the adjustment of real PID controllers, the value of the filter time constant $T_{f 1}$ is associated with the time constant of differentiation $T_{d 1}$ via the connection coefficient $K_{f}$ by the relation: 


$$
\mathrm{T}_{\mathrm{f} 1}=\frac{\mathrm{T}_{\mathrm{d} 1}}{\mathrm{~K}_{\mathrm{f}}}
$$

where $T_{d 1}$ - the time constant of differentiation with respect to the first-order derivative; $T_{f 1}-$ the time constant of the filter for the first-order derivative.

However, it should be noted that the controller adjustments should ensure optimal AAS performance while observing a given stability margin. While the structure and parameters of the filter should provide the optimal noise filtering for the calculus of derivatives. Therefore, the joining of the above parameters is not completely correct.

If to add, in addition to the operation of differentiation of the first order, the operation of real differentiation of the second order, in the structure of the PID controller, its transfer function, with filter time constants, takes the form of a PIDD² controller:

$$
\mathrm{W}_{\text {p.p. }}^{\text {PIDD }}(\mathrm{s})=\mathrm{K}_{\mathrm{p}} \cdot\left(1+\frac{1}{\mathrm{~T}_{\mathrm{I}} \cdot \mathrm{s}}+\frac{\mathrm{T}_{\mathrm{d} 1} \cdot \mathrm{s}}{\mathrm{T}_{\mathrm{f} 1} \cdot \mathrm{s}+1}+\frac{\mathrm{T}_{\mathrm{d} 1} \cdot \mathrm{T}_{\mathrm{d} 2} \cdot \mathrm{s}^{2}}{\left(\mathrm{~T}_{\mathrm{f} 1} \cdot \mathrm{s}+1\right) \cdot\left(\mathrm{T}_{\mathrm{f} 2} \cdot \mathrm{s}+1\right)}\right),
$$

where $\mathrm{K}_{\mathrm{p}}$ - the transfer factor of the controller; $\mathrm{T}_{\mathrm{I}}$ - the time constant of integration; $\mathrm{T}_{\mathrm{d} 1}, \mathrm{~T}_{\mathrm{d} 2}-$ the time constants for differentiation; $\mathrm{T}_{\mathrm{f} 1}, \mathrm{~T}_{\mathrm{f} 2}$ - the time constants of the filters $\mathrm{W}_{\mathrm{f} 1}(\mathrm{~s}), \mathrm{W}_{\mathrm{f} 2}(\mathrm{~s})$.

The ACS structural diagram, where a chain is added to the classical scheme of forming a PID algorithm with real differentiation that performs real second-order differentiation, thus realizing the PIDD ${ }^{2}$ control algorithm is shown in Fig. 1.

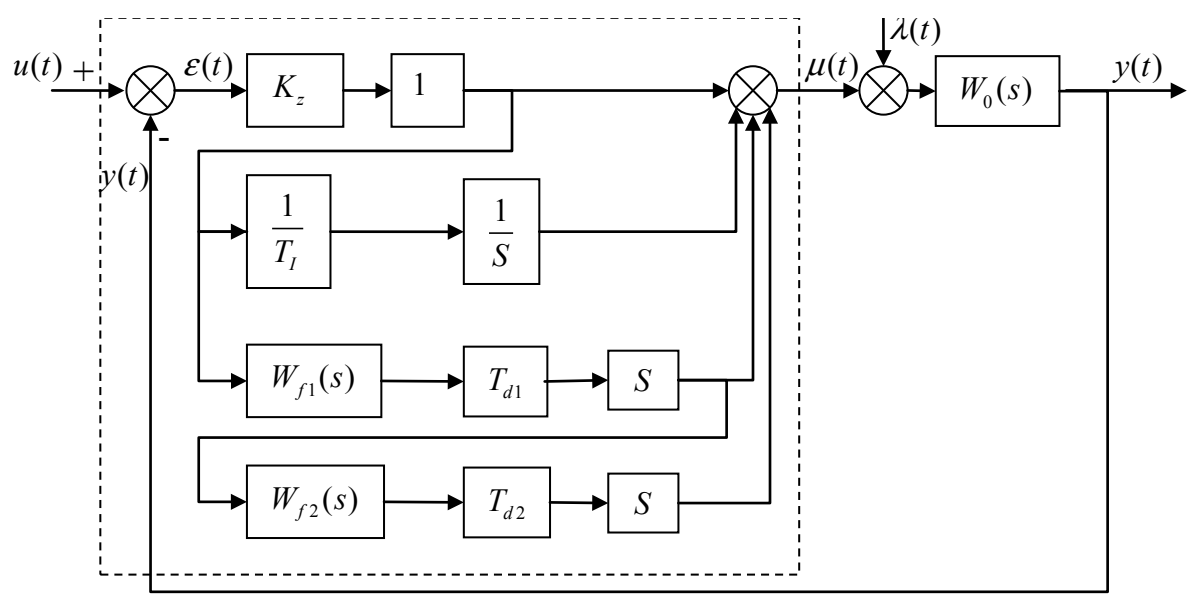

Fig. 1. ACS structural diagram with real $\mathrm{PIDD}^{2}$ controller

Directing time constants of the filters $\mathrm{T}_{\mathrm{f} 1}, \mathrm{~T}_{\mathrm{f} 2}$ to zero, let's obtain an idealized PIDD 2 controller that allows for the ideal differentiation of the deviation of a quantity that is regulated. The transfer function of such a controller is:

$$
\mathrm{W}_{\text {p.p. }}^{\mathrm{PIDD}^{2}}(\mathrm{~s})=\mathrm{K}_{\mathrm{p}} \cdot\left(1+\frac{1}{\mathrm{~T}_{\mathrm{I}} \cdot \mathrm{s}}+\mathrm{T}_{\mathrm{d} 1} \cdot \mathrm{s}+\mathrm{T}_{\mathrm{d} 1} \cdot \mathrm{T}_{\mathrm{d} 2} \cdot \mathrm{s}^{2}\right)
$$

Thus, if, in accordance with the transfer function (1), the real PID controller operates, then under real noise filtering conditions, a real PIDD $^{2}$ controller will function, in accordance with the transfer function (3).

The controller structure is shown in Fig. 1 and allows to obtain almost any control algorithm. For example, in the case $T_{I} \rightarrow \infty T_{d 1}=0, T_{d 2}=0$, the $P$ controller is realized, adding a finite value $\mathrm{T}_{\mathrm{u}}$, let's obtain the PI controller. When forming an algorithm with derivatives, the time constant of 
the filters $T_{f 1}, T_{f 2}$ plays an important role. By raising them, the real PIDD ${ }^{2}$ controller can practically be reduced to the PI controller and vice versa, directing the time constant of filters $\mathrm{T}_{\mathrm{f} 1}$, $\mathrm{T}_{\mathrm{f} 2}$ to zero, let's the PIDD ${ }^{2}$ controller. If the time constant $T_{\mathrm{f} 2}$ is directed to infinity, then let's obtain a real PID controller, and by directing $\mathrm{T}_{\mathrm{f} 1}$ to zero, let's obtain the ideal PID controller. In other words, the structure of the adjusing device shown in Fig. 1 allows to conduct a fairly thorough analysis and selection of the most effective controller operation algorithm for a real object with transport delay.

\section{Determination of automatic adjustment algorithm of multi-parametric PIDD ${ }^{2}$ controller in adaptive control system}

Since the optimum value $\mathrm{K}_{\mathrm{f}}$ from the point of view of the quality parameters of the control process is the magnitude that is directed at infinity, the value $\mathrm{K}_{\mathrm{f}}$ must be set depending on the specific operating conditions of the control system, primarily on the level of noise affecting the real differentiation procedure. To implement real PID algorithms in microprocessor controllers OMRON [20,21], it is recommended to choose a coefficient $\mathrm{K}_{\mathrm{f}}=5 \div 7$. The final value $\mathrm{K}_{\mathrm{f}}$ can only be selected during the putting into operation the control system on a real object.

As for the real PIDD ${ }^{2}$ controller, it is possivle to draw the following conclusion - having reasonably fulfilled the structural and parametric optimization of the filters $\mathrm{W}_{\mathrm{f} 1}(\mathrm{~s}), \mathrm{W}_{\mathrm{f} 2}(\mathrm{~s})$, proceeding from the task of suppressing high-frequency noise, it remains only to determine the adjusting parameters $K_{p}, T_{1}, T_{d 1}$ and $T_{d 2}$ for the control device synthesized in this way.

The proposed algorithm consists in a purposeful procedure for finding the optimal point with the maximum value of the transfer factor of the controller $\mathrm{K}_{\mathrm{p} \max }$ in the parameter space, taking into account the given stability margin. A block diagram of the algorithm for automatically finding the adjustments of the PIDD ${ }^{2}$ controller is shown in Fig. 2.

1. The initial values $\mathrm{K}_{\mathrm{p}}=0, \mathrm{~K}_{\mathrm{I}}=0, \mathrm{~K}_{\mathrm{d} 1}=0, \mathrm{~K}_{\mathrm{d} 2}=0$ and the steps to search for the desired values $\mathrm{K}_{\mathrm{p}_{-} \text {step }}, \mathrm{K}_{\mathrm{I}_{\text {_step }}}, \mathrm{K}_{\mathrm{d} 1_{\text {_step }}}, \mathrm{K}_{\mathrm{d} 2_{-} \text {step }}$ are specified. The approximate value of the steps for changing the adjustments is selected from the known relationships between the parameters of the object and the controller.

2. At the point $\mathrm{K}_{\mathrm{p}}=\mathrm{K}_{\mathrm{p}}+\mathrm{K}_{\mathrm{p}_{\mathrm{s}} \text { step }}, \mathrm{K}_{\mathrm{I}}=0, \mathrm{~K}_{\mathrm{d} 1}=0, \mathrm{~K}_{\mathrm{d} 2}=0$, the parameter $\mathrm{K}_{\mathrm{I}}$ increases to the maximum of the frequency responce. This value must not exceed the allowable limit $\mathrm{M}_{\max }$. This point will correspond to the optimal adjustment of the I-controller.

3. A search is made for the maximum $\mathrm{K}_{\mathrm{I}}$ on the line of the specified stability margin $\mathrm{M}_{\max }$. The found point corresponds to the optimal adjustment of the PI controller. For the case of control objects without self-aligning, the lines of a given stability margin in the parameter adjustments space begin to count from the origin and thus the algorithm finds point 1 at once.

4. The value $\mathrm{K}_{\mathrm{d} 1}$ increases by the step size $\mathrm{K}_{\mathrm{d} 1}=\mathrm{K}_{\mathrm{d} 1}+\mathrm{K}_{\mathrm{d} 1_{\text {_step }}}$. The value of the frequency oscillation index $M$ decreases with respect to the initial one. With this in mind, the value $K_{I}$ increases until the maximum frequency responce value of the system reaches the maximum.

5. A search is made for a maximum $\mathrm{K}_{\mathrm{I}}$ on the line of a given stability margin $\mathrm{M}_{\max }$ corresponding to the new value $\mathrm{K}_{\mathrm{d} 1}$.

6. The value $\mathrm{K}_{\mathrm{d} 2}$ increases by the step size $\mathrm{K}_{\mathrm{d} 2}=\mathrm{K}_{\mathrm{d} 2}+\mathrm{K}_{\mathrm{d} 2 \text { step }}$. The value of the frequency oscillation index $\mathrm{M}$ decreases further with respect to the initial one. With this in mind, an increase in the value occurs until the frequency responce maximum value of the system reaches maximum $M_{\max }$.

7. A search is made for a maximum $K_{I}$ on the line of a given stability margin $M_{\max }$ corresponding to the new value $\mathrm{K}_{\mathrm{d} 2}$.

Items 4-7 are repeated until the increase $\mathrm{K}_{\mathrm{d} 2}$ causes an increase in the value of the oscillation frequency index relatively $\mathrm{M}_{\max }$.

It is possible to note that the proposed algorithm is universal and provides the possibility, with a specified periodicity, to correct the controller pre-adjusting in accordance with the change in the dynamics of the control object. In the example (the MICE fuel preparation system), this fact significantly improves the quality of the regulation system and facilitates the work of the maintenance staff. 


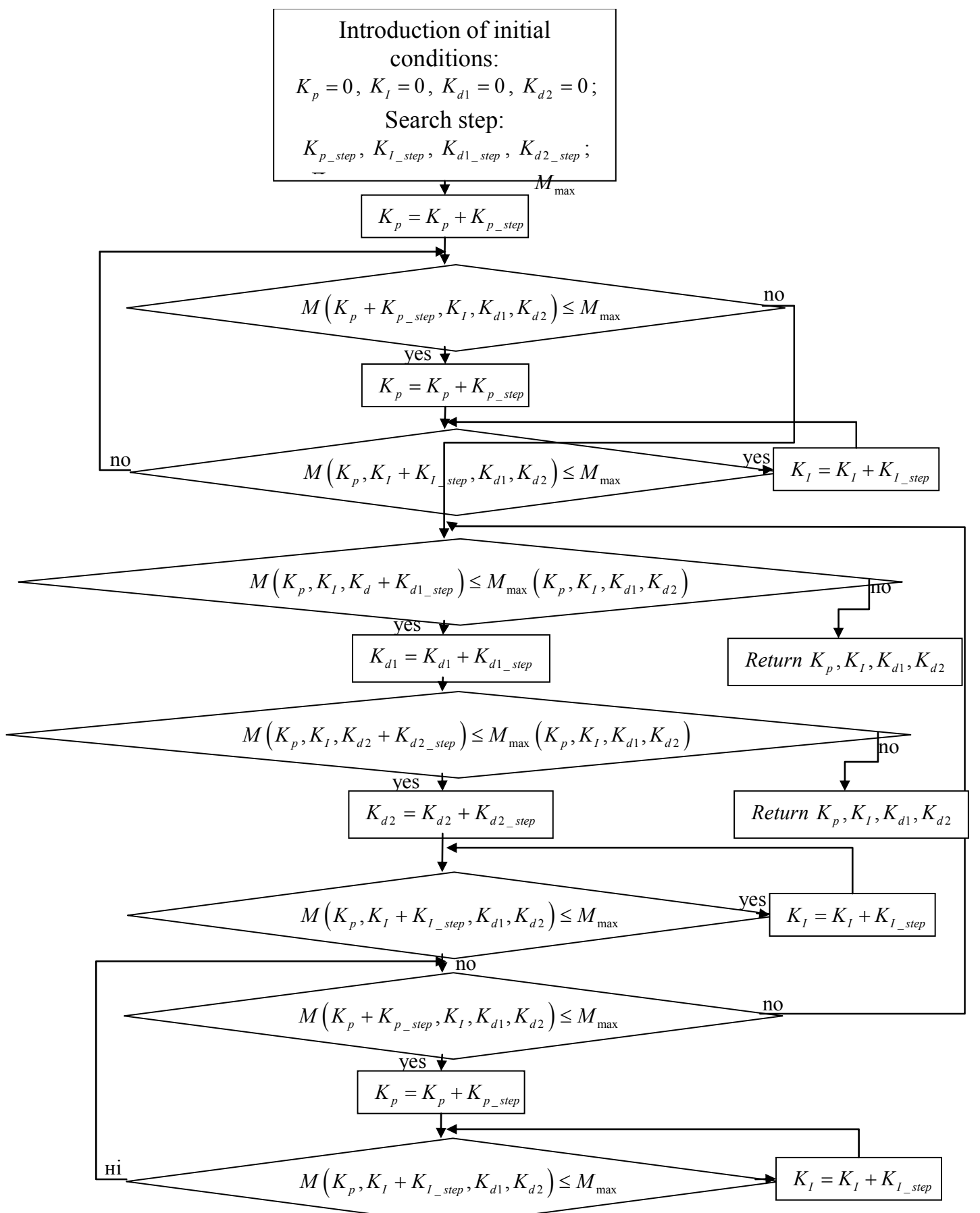

Fig. 2. Block diagram of algorithm for automatic finding of adjustments for PIDD $^{2}$ controller

\section{Results of the PIDD $^{2}$ controller adjustment in the adaptive control system using the pro- posed algorithm}

As an example, the procedure for identifying the object and optimizing the controller adjustment in a single-loop control system is illustrated [22, 23]. The real AAS is presented in the form of an imitation model that includes a control object with additive random noise and a PIDD ${ }^{2}$ controller with real differentiation. For clarity of results, the transient and the frequency response of an identical AAS with a PID controller are also presented. The transfer function of the control object [24] (maintenance of the set temperature of heavy fuel in the fuel preparation system), where the use of the PIDD $^{2}$ controller provides a noticeable effect on speed and transient response, looks like: 


$$
\mathrm{W}_{0}(\mathrm{~s})=\mathrm{K}_{0} \cdot \frac{\mathrm{e}^{-\tau_{0} \cdot \mathrm{s}}}{\left(\mathrm{T}_{0} \cdot \mathrm{s}+1\right)^{3}}
$$

where

$$
\mathrm{K}_{0}=1{ }^{\circ} \mathrm{C} / \% \text { RUPI, }
$$

where RUPI - regulating unit indicator; $\tau_{0}=0.43 \mathrm{~min} ; \mathrm{T}_{0}=1.42 \mathrm{~min}$.

The analysis is carried out using simulation models of single-loop AAS, which included the optimally adjusted PID controller with real differentiation and for AAS with PIDD ${ }^{2}$ controller adjusted according to the proposed algorithm.

Fig. 3 shows the curves of the transient and the frequency responce of a single-loop AAS including the optimally adjusted PID controller with real differentiation.
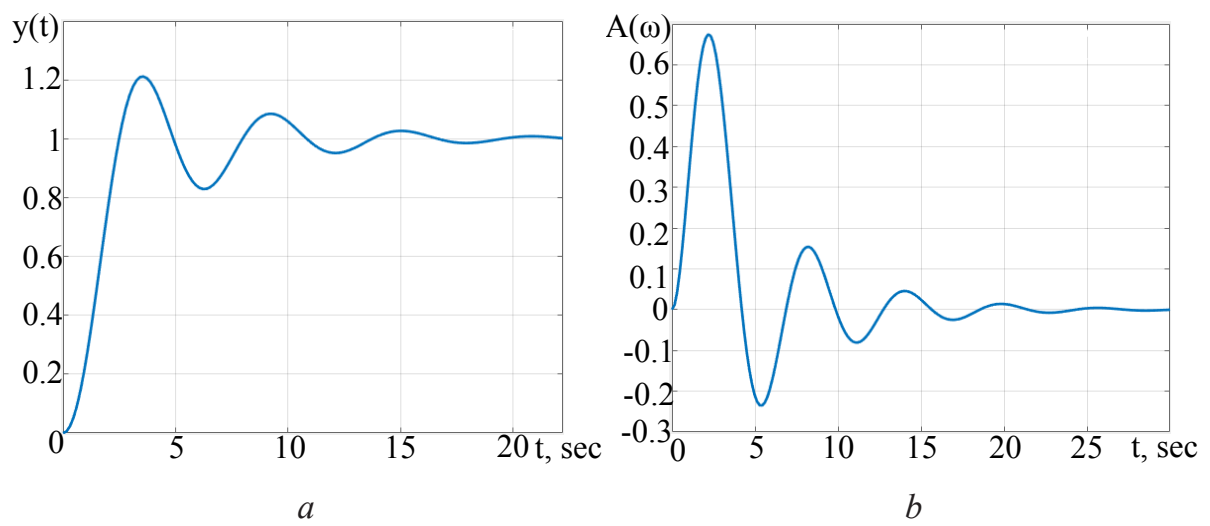

Fig. 3. AAS with a multi-parametric PID controller optimally adjusted to the original transfer function of the object: $a$ - transient process, $b$ - frequency response

Fig. 4 shows the curves of the transient and frequency response for a single-loop AAS with a $\mathrm{PID}^{\mathrm{D} 2}$ controller optimally adjusted using the presented algorithm.
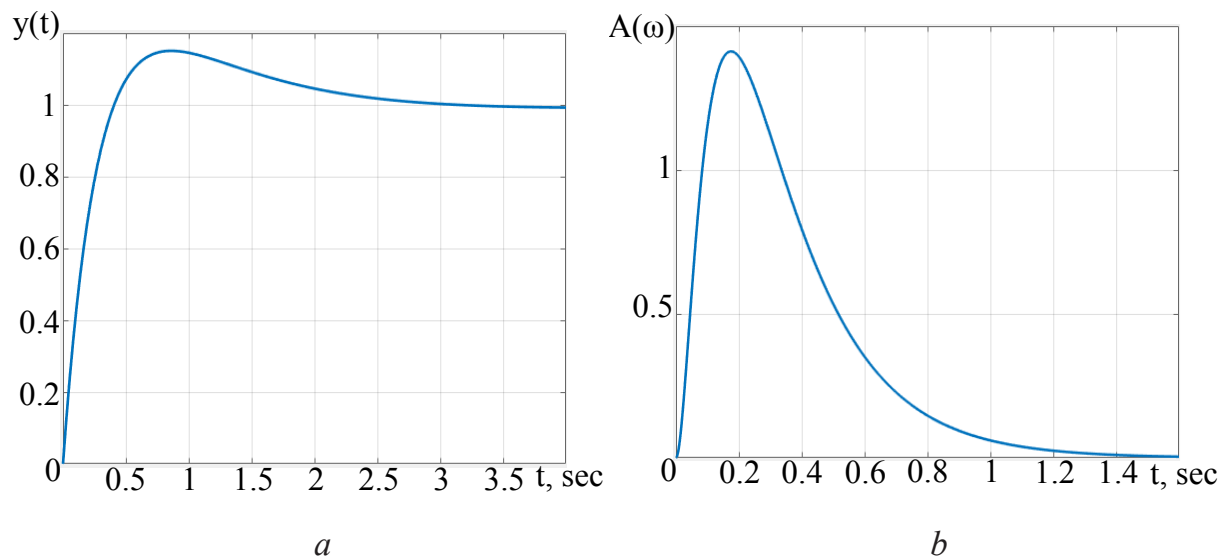

Fig. 4. AAS with a multi-parametric PIDD ${ }^{2}$ controller, optimally adjusted to the original transfer function of the object according to the proposed algorithm: $a$ - transient process, $b$ - frequency response

The results of the AAS periodic adaptation, due to the change in the dynamics of the controlled object, are shown in Fig. 5. Transient process and frequency responce are depicted under the condition that the dynamics of the real control object changes regardless of the periodicity of the re-adjusting of the controller parameters by a given algorithm. 


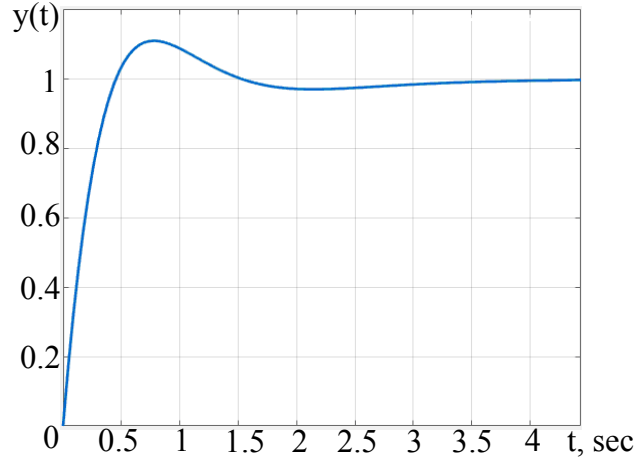

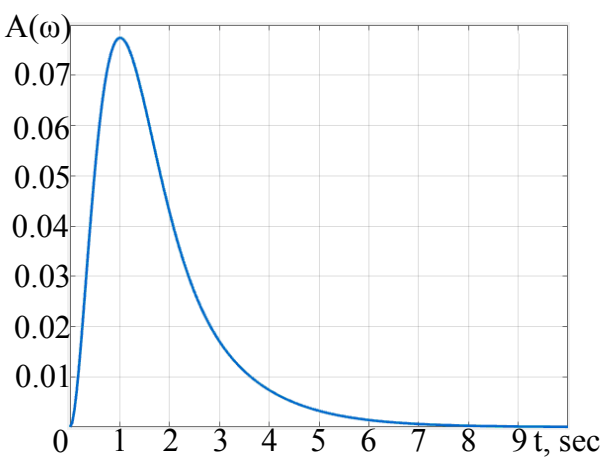

$b$

Fig. 5. AAS with a multi-parametric $\mathrm{PIDD}^{2}$ controller, optimally adjusted to the original transfer function of the object according to the proposed algorithm, when the dynamics of the control object changes: $a$ - transient process, $b$ - frequency responce.

The results of a comparative analysis of PID and PIDD ${ }^{2}$ controller-based adaptive control systems are determined to a significant degree by the dynamic characteristics of the control object (MICE fuel preparation system [25]). Therefore, the obtained results should be defined as a particular case for a particular controlled object.

\section{Discussion of the PIDD ${ }^{2}$ controller research result in an adaptive control system using the proposed algorithm}

Transient processes and frequency characteristics curves optimally adjusted to the original transfer function of the object, adaptive control systems with analyzed PID and PIDD ${ }^{2}$ controllers are presented in Fig. 3, 4. The nature of the changes in transients and frequency response for the same adjustments, but with a change in the dynamics of the control object, for the adaptive system with a PIDD ${ }^{2}$ controller is shown in Fig. 5. By the type of change in the curves of the transient processes and the values of the maximum values of the frequency response, one can judge the relative sensitivity of systems and analyze them.

In general, analyzing the graphs presented in Fig. 3-5, it is possible to state the following statements.

- adjustment quality in the adaptive system with PIDD $^{2}$ control and the proposed algorithm for finding the optimal parameters of the latter, if to estimate by the integral criterion, increases 4-fold in comparison with the optimally AAS with a PID controller. The maximum deviation of the control parameter decreases by a factor of 0.75 , and the oscillation index by a factor of 5 . This means that the control system with the optimally adjusted PIDD $^{2}$ controller regulates the quality control parameters in comparison with the PID controller system.

- it is shown from the curves of the change in the transient and the frequency response of the system in Fig. 3, 4 that the dynamics of the control object has changed, and controller adjustments have remained the same as before, that the oscillation index characterizing the stability reserve of the system has increased almost twice as compared with the initial one. And the maximum value of the deviation of the control parameter has decreased. So the performance quality of the adaptive control system remained at a level, compared with the initial state of the controlled object.

Also, it should be added that the presented algorithm for finding optimal adjustments can also be used to obtain optimal PID controller parameters in an adaptive control system, with only minor changes in algorithm steps.

Thus, the proposed method practically does not impose restrictions on the structure of controllers, as well as on the number of variables of the latter.

However, with the increase in the number of control parameters, it increases noticeably when solving the task of finding optimal settings, it can impose some limitations on attempts to 
re-adjust the controllers at a pace with the process, and as a result - to implement adaptive models. However, it should be noted that in this situation everything depends on the performance of computer technology. In addition, a significant role is assigned to the necessary time intervals between the next adjustments of the settings.

\section{Conclusions}

1. Identification of the transfer function of the PIDD $^{2}$ controller with the transfer functions of the differentiation filters of the first and second orders makes it possible to obtain the structure of the control device. To determine the algorithm for finding optimal controller adjustments in the adaptive ACS of the object with transport delay.

2. The determination of the algorithm for a purposeful search for the optimal point with the maximum coefficient of transfer to the controller of the selected stability margin is fairly easily solved by numerical methods. Structural implementation of the algorithm indicates its versatility and the ability to change system adjustments at a specified frequency, or at the request of maintenance staff.

3. A comparative analysis of transients and frequency response in PIDD²-based adaptive control system, using the proposed algorithm for finding optimal adjustments and conventional systems with a PID controller on the example of the mathematical model of MICE fuel preparation system. As a result of the analysis, an increase in the quality of the system performance with the PIDD $^{2}$ controller is noted.

\section{References}

[1] ER Schiffahrt Energy Efficiency. Available at: http://www.er-ship.com

[2] Simanenkov, A. L., Rozhkov, S. O. (2015). Analiz osnovnikh parametriv roboti sudnovogo dviguna vnutrishnogo zgoryannya. Sistemi upravlinnya, navigacii ta zv'yazku, 3 (35), 44-48.

[3] Simanenkov, A. L., Rozhkov, S. O. (2016). Sintez sistemi keruvannya v'yazkosti paliva. Suchasni Informatciyni ta innovatciyni tehnologiyi na transporti. 279-283.

[4] Różowicz, S., Tofil, S. (2016). The influence of impurities on the operation of selected fuel ignition systems in combustion engines. Archives of Electrical Engineering, 65 (2). doi: 10.1515/aee-2016-0026

[5] Kondratenko, A. N. (2016). Koncepciya ocenki efektivnosti upravleniya ekologicheskoy bezopasnostyu procesa eksplyatacui energeticheskix ystanovok s porshnevumi DVS. Combustion engines, $2,68-72$.

[6] Lind, S., Aßmann, S., Zigan, L., Will, S. (2016). Fluorescence characteristics of the fuel tracers triethylamine and trimethylamine for the investigation of fuel distribution in internal combustion engines. Applied Optics, 55 (7), 1551. doi: 10.1364/ao.55.001551

[7] Feng, L., Du, B., Tian, J., Long, W., Tang, B. (2015). Combustion Performance and Emission Characteristics of a Diesel Engine Using a Water-Emulsified Heavy Fuel Oil and Light Diesel Blend. Energies, 8 (12), 13628-13640. doi: 10.3390/en81212387

[8] Corneliu, M. (2015). The marine heavy fuel ignition and combustion by plasma. Fiabilitate si Durabilitate, 1, 220-228.

[9] Benajes, J., García, A., Monsalve-Serrano, J., Boronat, V. (2016). Dual-Fuel Combustion for Future Clean and Efficient Compression Ignition Engines. Applied Sciences, 7 (1), 36. doi: 10.3390/app7010036

[10] Blagojevic, I., Vorotovic, G., Ivanovic, G., Jankovic, S., Popovic, V. (2013). Energy efficiency improvement by gear shifting optimization. Thermal Science, 17 (1), 91-105. doi: 10.2298/tsci120129035b

[11] Repin, A. I., Smirnov, N. I., Sabanin, V. R. (2008). Identifikaciya i adaptaciya SAR s ispol'zovaniem ehvolyucionnihkh algoritmov optimizacii. Promihshlennihe ASU i kontrollerih, 03, 31-35.

[12] Smirnov, N. I., Sabanin, V. R., Repin, A. I. (2007). Strukturnaya realizaciya i optimal'naya nastroyika mnogoparametricheskogo PIDD2-regulyatora s real'nim differencirovaniem. Promihshlennihe ASU i kontrollerih, 11, 34-39.

[13] Smirnov, N. I., Sabanin, V. R., Repin, A. I. (2007). O korrektnosti nastroyiki PID-regulyatora pri approksimacii perekhodnoy kharakteristiki ob'ekta regulirovaniya aperiodicheskim zvenom s transportnihm zapazdihvaniem. Promihshlennihe ASU i kontrollerih, 01, 35-39. 
[14] Varlamov, I. G., Serezhin, L. P., Filimonov, B. V. (2004). Gaechniy klyuch dlya naladchika SAR. Promihshlennihe ASU i kontrollerih, 12, 73-78.

[15] Smirnov, N. I., Sharovin, I. M. (2009). O vihbore kriteriya optimal'nosti v chislennihkh metodakh rascheta SAR. Promihshlennihe ASU i kontrollerih, 5, 16-21.

[16] Avtomaticheskie regulyatoryi v sistemah upravleniya i ih nastroyka. Available at: http://www. compitech.ru/html.cgi/arhiv/03_05/stat_114.htm

[17] Rotach, V. Ya. (2006). K raschetu optimaljnihkh parametrov real'nih PID-regulyatorov po ehkspertnihm kriteriyam. Promihshlennihe ASU i kontrollerih, 2, 22-29.

[18] Ray, H. W. (1981). Advanced process control. McGrow-Hill Book Company, New York, 365.

[19] Aranda, J., Armada, J. M., De la Cruz, J. M. (2004). Automation for the Maritime Industries. Produccion Grafica Multimedia, PGM, Madrid, Spain, 284.

[20] OMRON Programmable controllers Advanced User manual. Available at: http://www. ia.omron.com

[21] Bolton, W. (2006). Programmable Logic Controllers. Elsevier, 303. doi: 10.1016/b978075068112-4/50019-x

[22] Dukkipati, R. V. (2006). Analusis and Design of Control Systems Using MATLAB. New age international (P) Limited, New Delhi, 269.

[23] Attaway, S. (2017). MATLAB: A Practical Introduction to Programming and Problem Solving. Butterworth-Heinmann, Woburn, 598.

[24] Simanenkov, A. L., Rozhkov, S. O., Timofeev, K. V. (2016). Modelyuvannya sistemi regulyuvannya vyazkosti vazhkih paliv. Naukoviy visnik Hersonskoyi derzhavnoyi morskoyi akademyi, 2 (15), 181-190.

[25] RT-flex Operation\&Practical Training course. Available at: http://dieselturbo.man.eu 